\title{
The acetylator phenotypes of Saudi Arabians with coronary arterial atheroma
}

\author{
David A Price Evans, John Wicks, Jackie Higgins, Milagros Assisto
}

\begin{abstract}
The acetylator phenotypes were determined by means of a sulfamethazine test in 101 Saudi Arabian patients with authenticated coronary atheroma; 65 were found to be slow acetylators. This distribution of phenotypes is not significantly different from that in 220 controls, 148 of whom were slow acetylators. This finding makes it unlikely that compounds containing a primary aromatic amino or a hydrazino group are involved in the aetiology or pathogenesis of coronary atheroma.
\end{abstract}

Since the discovery of the $\mathrm{N}$-acetyltransferase polymorphism, many surveys have been made to see if there are statistical associations of spontaneous disorders with either phenotype. ${ }^{1}$

In the cardiological field there have been relatively few such observations and most of them have been made incidentally to the main objectives of the surveys. As far as the authors are aware there is no published investigation to discover whether coronary arterial atheroma is associated with an acetylator phenotype. The purpose of the investigation reported here was to remedy this defect.

The natural substrates of the polymorphic enzyme are unknown, but are likely to be primary aromatic amines or hydrazine compounds. There is evidence that the former compounds are involved in the development of bladder cancer and this has been the basis of investigating the acetylator phenotype frequency in this disorder. Apart from that example, statistical associations of either phenotype with disorders have been sought on a speculative basis. The philosophy behind this approach is that a significant association would suggest that aromatic amines or hydrazine compounds might be involved in the causation of the disorder in question.

C123 Riyadh Armed Forces Hospital, PO Box 7897, Riyadh 11159, Kingdom of Saudi Arabia.

D A Price Evans, J Wicks, J Higgins, M Assisto

Correspondence to Professor Price Evans.

Received for publication 28 June 1990.

Revised version accepted for publication 14 September 1990.

\section{Patients and methods}

PATIENTS

The patients were all Saudi Arabian citizens investigated for cardiac disorders in the Riyadh Armed Forces Hospital. The diagnosis was based on one or more of the following illnesses and procedures from which the patients had fully recovered at the time their phenotyping tests were performed: classical myocardial infarctions (2), coronary angiography showing the lesions (60), balloon angioplasty (20), and coronary artery bypass surgery (19), giving a total of 101 (91M, 10F).

These patients received their acetylator phenotyping test while they were inpatients in this hospital. Thirty-one patients were diabetic; two were receiving insulin and 16 were being treated by diet only.

\section{ACETYLATOR PHENOTYPING PROCEDURE}

The method of series II of Evans ${ }^{2}$ was used. The medications the patients were receiving were withheld on the morning of the test whenever possible. The dosage range of sulfamethazine (SMZ syn sulphadimidine) was 500 to $1000 \mathrm{mg}$.

\section{CONTROLS}

The controls were derived from three sources: (1) rural Saudis as published by Islam ${ }^{3}$; (2) Saudi controls as published by Evans $e t a l^{4}$; and (3) Saudi 'watchers' phenotyped during the course of the present study ('watchers' are healthy persons, often relatives, who stay with the patient in hospital to tend to his needs). These watchers were not related to the patients being phenotyped.

\section{INFORMED CONSENT}

This scheme of research was approved by the Ethical Committee of the Riyadh Armed Forces Hospital. All patients and control subjects gave their informed consent.

\section{Results}

The results of phenotyping the patients are shown in the figure and table 1 . The composition of the control 


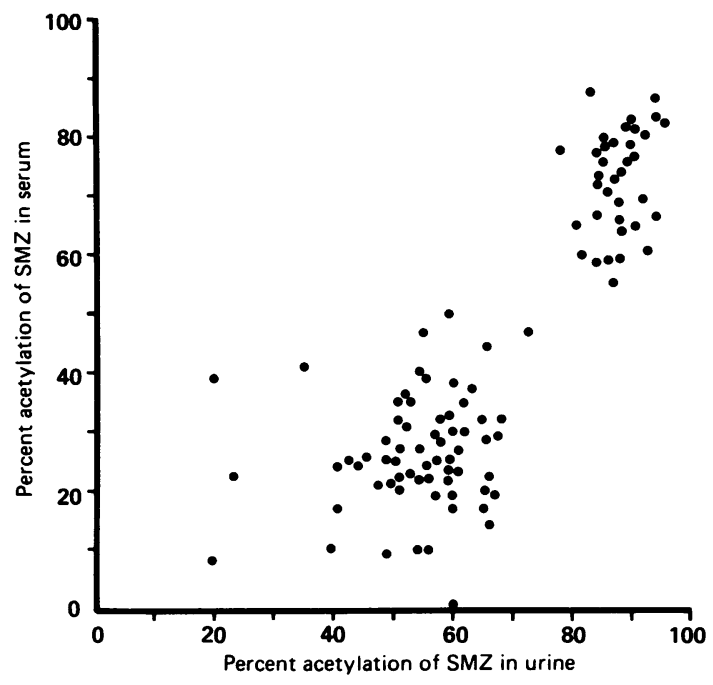

Sulfamethazine (SMZ) phenotyping data on 101 Saudi Arabianswith coronary arterial atheroma.

Table 1 Phenotypes of Saudi Arabian coronary artery atheroma patients.

\begin{tabular}{lcc}
\hline Category & $\begin{array}{c}\text { Slow } \\
\text { acetylators }\end{array}$ & $\begin{array}{c}\text { Rapid } \\
\text { acetylators }\end{array}$ \\
\hline $\begin{array}{l}\text { Non-diabetic } \\
\text { Diabetic }\end{array}$ & 44 & 26 \\
& 21 & 10
\end{tabular}

$\chi_{1}^{2}=0 \cdot 22, p>0.50$.

Table 2 Phenotypes of Saudi Arabian control subjects.

\begin{tabular}{lcc}
\hline Source & $\begin{array}{c}\text { Slow } \\
\text { acetylators }\end{array}$ & $\begin{array}{c}\text { Rapid } \\
\text { acetylators }\end{array}$ \\
\hline Islam $^{3}$ & 74 & 35 \\
Evans et al $^{4}$ & 67 & 33 \\
Present survey & 7 & 4 \\
Total & 148 & 72 \\
\hline
\end{tabular}

$\chi_{2}^{2}=0.09, \mathrm{p}>0.90$. groups is shown in table 2 . The comparison between all patients and controls gives $\chi_{1}^{2}=0.26(p>0.50)$. When the non-diabetic coronary patients were compared with controls $\chi_{1}^{2}=>0.46(p>0.50)$.

\section{Discussion}

The separation shown in the figure indicates the robustness of the phenotyping procedure in the presence of the many drugs which the patients were receiving. No adverse reactions were encountered to the phenotyping doses of sulfamethazine.

The possibility of a type II error arises, in other words, a null hypothesis being accepted when in truth a significant difference exists between the groups compared. This could come about because of coronary arterial disease in the controls. This does not seem a serious consideration because the controls were fit, well, and younger than the patients.

Another possible objection might be that acetylating capacity might be impaired in some way by the disease process in the patients. The evidence is against this because if it were present it would increase the intraphenotypic variances and so diminish the distinct separation between the phenotypes. The figure shows that this did not occur.

Since no significant association has been found in this survey between coronary artery atheromatous disease and either acetylator phenotype, it seems very unlikely that primary aromatic amines or hydrazine compounds play a role in the production of the disorder.

The authors thank the Research and Ethical Committee of the Riyadh Armed Forces Hospital (Chairman Mohamed Al Fagih FRCS) for financial assistance.

1 Evans DAP. N-acetyltransferase. Pharmacol Ther 1989;42: 157-234.

2 Evans DAP. An improved and simplified method of detecting the acetylator phenotype. $\mathcal{F}$ Med Genet 1969;6:405-7.

3 Islam SI. Pólymorphic acetylation of sulphamethazine in rural bedouin and urban-dwellers in Saudi Arabia. Xenobiotica 1982;12:323-8.

4 Evans DAP, Paterson S, Francisco P, Alvarez G. The acetylator phenotypes of Saudi Arabian diabetics. 7 Med Genet 1985;22: 479-83. 